\title{
A Study of Small Solar Thermal Power Generation Device Based on Shape Memory Alloy
}

\author{
Liangcheng Cheng
}

North China Electric Power University, Beijing, 102206, China

479146353@qq.com

Keywords : Solar thermal power generation, Shape Memory Alloy, Power generation efficiency

\begin{abstract}
Solar thermal power generation device is based on Shape Memory Alloy, utilizing the shape memory alloy effect to convert thermal energy to electrical energy. Since clean energy, like solar power can contribute to sustainable economic development, we design a solar power generation device: Solar thermal power generation device based on Shape Memory Alloy. Shape Memory Alloy (SMA) refers to the alloy that has Shape Memory Effect. Mechanical properties of Shape Memory Alloy enable it to fulfill shape memory function mainly as the outside temperature changes or external force is applied. The shape of shape memory alloy changes along with temperature change. The device we design uses this feature to drive the wheels and thus provide driving force to direct current electricity machine. And then the direct current electricity will be sent to electrical appliance, eventually achieving the conversion from thermal energy to electrical energy.
\end{abstract}

\section{Introduction}

Solar energy belongs to an ideal energy in low-carbon society as a green and clean renewable energy. At the same time, it's the greenest, most durable, safest and most reliable energy alternatives. The research for solar thermal power generation technology is important, practical and economic.

We use the characteristic of shape changes of shape memory alloy (SAM) when temperature changes to realize a new way to use solar energy to generate electricity.

Traditional solar thermal power generation aggregates the solar energy to heat working substance and drive turbine to generate power. The shape of SMA changes as temperature varies. When placed in the working substance, it can convert the heat energy of working substance to mechanical energy and realize the high-efficiency reusing of energy. The development of this technology is a new path based on the traditional photo-thermal optoelectronics and creates a new idea, which is of great significance to the multi-level utilization and efficient use of energy. This technology can be applied to the lighting and charging of general family and can also be extended to the waste heat power generation in power plant and other fields.

\section{The Basic Theory of Shape Memory Alloy(SMA)}

Shape memory alloy is a kind of alloy which has shape memory effect. It is a kind of multi-functional intelligent materials which has sensing and driving functions, can work outside while getting heat energy. And it will have a wide range of applications in engineering and medical field in the future.

The mechanical property of the shape memory alloy (hereinafter referred to as SMA) is mainly that SMA has a small yield strength in the low temperature phase and it's easy to produce a large plastic deformation up to $20 \%$ through the small external force, which the general metal can't achieve. When heated to high temperature above end temperature of the reverse phase transition, it can quickly and completely return to the shape before the plastic deformation in the low temperature and its yield stress in the high temperature is much higher than that in the low temperature. Throughout the progress, the shape memory alloy not only produces a large 
displacement deformation, but also outputs a large recover stress and works outside.

Shape memory alloy mainly includes nickel-based, copper-based and iron-based categories. At present, what is the most widely used is TiNi-based alloy because its memory characteristic is stable and has a long memory life.

\section{Experiment Equipment}

In view of the issue of photo-thermal power generation, we designed a photo-thermal power generation device based on shape memory alloy as shown in Figure $1(a, b)$.

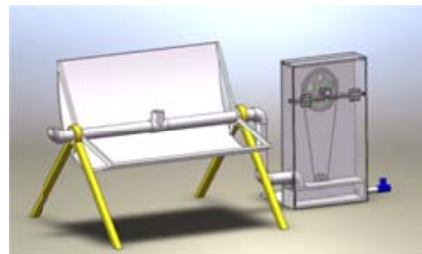

Fig. 1(a) 3D graphic

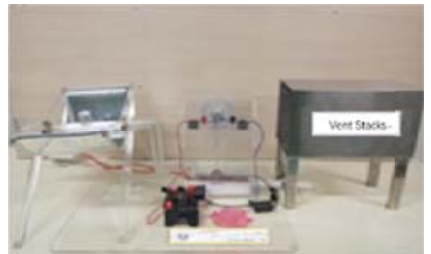

Fig. 1(b) Physical graphic

3.1 The Module of Shape memory alloy wire power generation.

3.1.1 Shape memory alloy wire.This design uses shape memory alloy wire as shown in Figure 2. We wrap the alloy wire around the big wheel and the small wheel. Then the alloy wire produces deformation under high temperature and drives wheel to rotate. Shape memory alloy wire has good flexibility and it's not easy to break, so they are suitable for power generation.

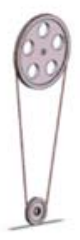

Fig. 2 The matching between SMA wire and wheel

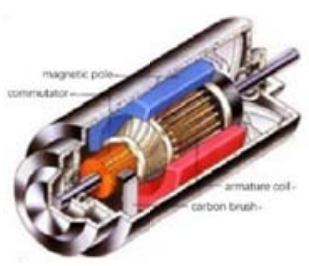

Fig. 3 Schematic diagram of DC generator structure

\subsubsection{Analysis of reason for rotation of wheel.}

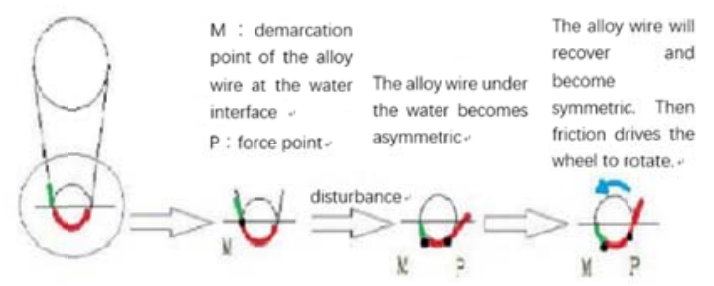

Fig. 4 Illustration of reason for rotation

Shape memory alloy wire in the low temperature condition can produce any deformation [3]. In this device, the shape of the alloy wire at low temperature coincides with the positional relationship and size of the large wheel and small wheel in the device. At high temperature, the shape of the alloy wire is a regular circle.

As shown in Figure 4, point $\mathrm{M}$ is the demarcation point of the alloy wire at the working substance (water) interface. When the wheel is disturbed, the green section keeps the original shape and goes into the working substance. At present, the shape memory alloy wire immediately has a trend to return to the circular shape under high temperature. In this trend, point $\mathrm{M}$ moves from the location in the third screen to the location in the fourth screen. Point $\mathrm{P}$ is the force point, the alloy wire quickly drives small wheel to rotate and provides constant force for the small wheel.

3.1.3 The module of power conversion and utilization. DC generator is a device which can convert mechanical power to DC electrical power. 


\subsection{Construction of Shape Memory Alloy Power Generation Experimental Platform.}

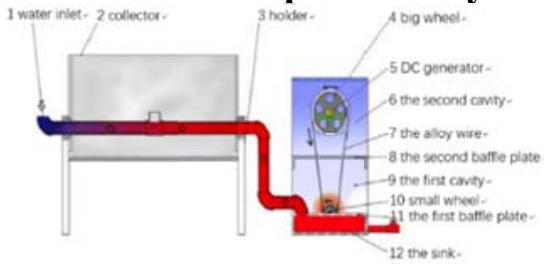

Fig. 5 Thermal imaging analysis graphic

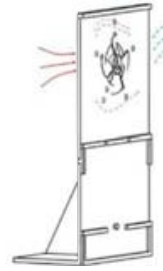

Fig. 6 The stereogram of gas flowing

As shown in Figure 5, the collector 2 supported by the holder 3 is a paraboloid. The working substance (water) is poured into the water inlet 1 and flows through the heat collector 2 . The heated water flows into the sink 12 at the bottom through the pipeline, and the cold working substance is heated to high temperature by the solar radiation. Shape memory alloy wire produces deformation under high temperature and drives the rotation of small wheel 10. Then rotation of small wheel 10 drives the rotation of big wheel 4 so that the heat energy of working substance converts to the mechanical energy of big wheel 4 and small wheel 10. There is another part of the friction heat and radiation loss. The DC generator 5 is mounted coaxially with the big wheel 4 . The rotation of the big wheel 4 will drive the generator's rotor to rotate. At last, cutting magnetic field line will induce the alternative induced electromotive force and mechanical energy is converted to electric energy.

In addition, the second cavity 6 will be further cooled by the action of environment (especially the wind) so that the shape memory effect of the alloy wire 7 will be further highlighted to achieve high speed operation of the wheels. The air flowing is shown in Figure 6.

In order to monitor the temperature of working substance (water) in real time, we set temperature measuring point in the sink to ensure the stability of power generation.

\section{4 experimental process}

4.1 No-load experiment.Disconnect the switch $\mathrm{S} 1$ which is connected to the load and close the switch S2.

The voltage at both ends of the DC generator is measured by a voltmeter. Measure the speed using a tachometer and measure the water temperature in the sink with digital thermometer. Use a camera to shoota scene, including voltmeter, speedometer and thermometer. After the experiment, playback the video to record data.

4.2 Load experiment.Close switch S1 connected the load, and the switch S2 connected voltage and ammeter is still closed. At this time, the electric energy generated by the DC generator is transmitted to a $13 \Omega$ resistor through an external circuit.

The power of resistance is monitored in real time by voltmeter and ammeter. At the same time, monitor of working temperature with a thermometer. The relationship between power $P$ and temperature difference $\Delta T$ is obtained from the experiment.

\section{Data recording and processing}

\subsection{Power generation performance test.}

\subsubsection{No-load test:}

We obtained the following experimental data through the no-load experiment of starting temperature of 90 degrees centigrade: 
Table 1 No-load test data

\begin{tabular}{c|c|c|c}
\hline temperature $\left(\mathrm{C}^{\circ}\right)$ & temperature difference $\Delta \mathrm{T}(\mathrm{K})$ & VoltageU $(\mathrm{V})$ & rotate speed $(\mathrm{r} / \mathrm{min})$ \\
\hline 91.2 & 75.2 & 1.8 & 1253 \\
91.1 & 75.1 & 1.8 & 1250 \\
90.3 & 74.3 & 1.7 & 1223 \\
89.5 & 73.5 & 1.7 & 1210 \\
88.8 & 72.8 & 1.6 & 1204 \\
87.9 & 71.9 & 1.6 & 1036 \\
87.2 & 71.2 & 1.5 & 758.5 \\
86.5 & 70.5 & 1.5 & 648 \\
85.5 & 69.5 & 1.7 & 423.3 \\
84.9 & 68.9 & 1.7 & 421.3 \\
83.3 & 67.3 & 1.7 & 411.1 \\
82.6 & 66.6 & 1.6 & 393.2 \\
82.2 & 66.2 & 1.6 & 380.2 \\
\hline
\end{tabular}

Using MATLAB linear fitting, no-load voltage U- $\Delta$ T relation:

$U=0.0233 \Delta T-0.0094$

\subsubsection{Load test:}

In the same way, we get a series of $U, I, P, T, n$ experimental data through the starting temperature of $90^{\circ} \mathrm{C}$ load experiment, as shown in the following table:

Table 2 Load test data

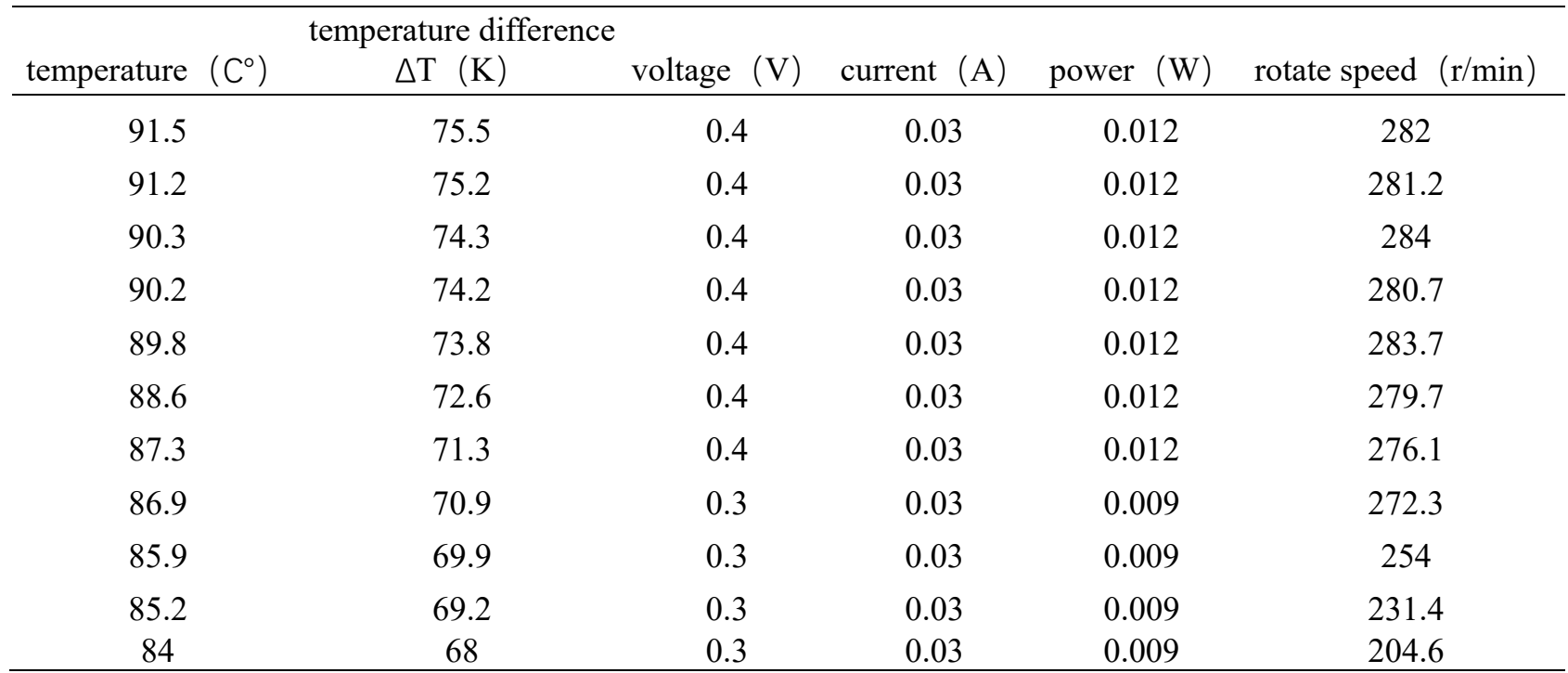

By using MATLAB linear fitting, we get the function relationship between power $\mathrm{P}$ and temperature difference $\Delta_{\mathrm{T}}$ :

$$
P=0.0005 \Delta T-0.0258
$$

It can be seen that the temperature difference is bigger and the power is higher when the device is in a certain temperature range.

5.2 System comprehensive benefit calculation.In fact, the entire power system is to convert heat into mechanical energy then into electricity. System comprehensive benefit calculation is efficiency calculation of a device that utilizes heat energy.

The data of the load power and the temperature difference in the $10 \mathrm{~s}$ are obtained by the performance test: 
Table 3 Experimental data of temperature and power

\begin{tabular}{|c|c|c|c|c|}
\hline $\begin{array}{l}\text { temperature } \\
\left(\mathrm{C}^{\circ}\right)\end{array}$ & $\begin{array}{l}\text { temperature } \\
\text { difference } \\
\Delta \mathrm{T}(\mathrm{K})\end{array}$ & voltage & (V) current (A) & power $(\mathrm{W})$ \\
\hline 91.5 & 75.5 & 0.4 & 0.03 & 0.012 \\
\hline 91.2 & 75.2 & 0.4 & 0.03 & 0.012 \\
\hline 90.3 & 74.3 & 0.4 & 0.03 & 0.012 \\
\hline 90.2 & 74.2 & 0.4 & 0.03 & 0.012 \\
\hline 89.8 & 73.8 & 0.4 & 0.03 & 0.012 \\
\hline
\end{tabular}

Based on the above data, we can get the energy absorbed by the load in $10 \mathrm{~s}$ : $W=P t=0.03 \times 10=3 W$

In this time the water temperature from $91.5^{\circ} \mathrm{C}$ down to $89.8^{\circ} \mathrm{C}$. The size of the sink, length $a=60 \mathrm{~mm}$, width $b=40 \mathrm{~mm}$ and height $c=25 \mathrm{~mm}$. The volume of water $V=60 \mathrm{~cm}^{3}$, and the weight of the water $m=\rho V=60 \mathrm{~g}$

The change of the heat of water in 10s Overall efficiency of the system

$Q=\mathrm{cm} \Delta T=\left(4.2 \times 10^{3}\right) \times\left(60 \times 10^{-3}\right) \times 1.8 \mathrm{~J}=453.6 \mathrm{~J}$

system comprehensive efficiency

$\eta=\frac{W}{Q} \times 100 \%=\frac{3}{453.6} \times 100 \%=0.026 \%$

The heat of the water is the heat of the water in the sink. But only a fraction of the water contacts with the memory alloy, so the system efficiency is low.

\section{Summary}

6.1 Performance analysis of shape memory alloy power generation system.According to the previous data, it's easy to know that because of the poor stability of the shape memory alloy power generation system and small electric energy, the maximum value of the no-load voltage is about $1.8 \mathrm{~V}$. Due to the poor thermal insulation of the device, the $1.8 \mathrm{~V}$ voltage can't be maintained for a long time. When the load is stable, voltage can be maintained at around $0.3 \mathrm{~V}$, and the current is only $0.03 \mathrm{~A}$. Visibly the system load capacity is not very good.

Shape memory effect of shape memory alloy can be produced under a certain temperature difference, so the cooling device is very important. Therefore, we use a fan for the upper part of the shape memory alloy wire cooling, so that the memory effect of the alloy wire can have a full play.

In conclusion, the experimental platform has the following shortcomings: (1)a voltage is not high enough; (2) the load capacity is weak; (3)the cooling effect is poor; (4) the poor thermal insulation properties.

6.2 Improvement direction.For these deficiencies, we propose the following improvements:

1. Increase the wheels of the channel.

2. Increase the size of the entire system.

3. Improve the insulation performance of the system.

6.3 Prospects. At present, the state vigorously promotes energy-saving emission reduction and sustainable development. Based on shape memory alloy thermal power generation device, opens up a new way of solar energy utilization. It will improve the utilization of energy further.

The photo-thermal generation technology based on shape memory alloy is used in industry and daily life. On the one hand, it can reduce the loss of energy. On the other hand, if this part of the energy is provided to family users, it can save energy, reduce the pressure of power supply, and realize energy saving and reduce emission in a sense.

\section{References}

[1] X.P.Tang. Research on SMA's Mechanical Property and Its Application on Fan Clutch. Master's 
Dissertation of Chongqing Institution of Technology, 2008. (In Chinese)

[2] Y.F.Yuan. Design and control of shape memory alloy actuator. Master's Dissertation of Liaoning Technology University, 2003. (In Chinese)

[3] Y.Song. The Design of Structure and Experiment of on flexible biomimetic fish fin based on Shape Memory Ally. Master's Dissertation of University of Science and Technology of China, 2009. (In Chinese)

[4] X.Gao. The research of the power mechanism driven by Shape memory alloy. Master's Dissertation of North University of China, 2014. (In Chinese) 